\title{
Efficacy of some diagnostic procedures used for diagnosis of Trypanosomiasis in camels
}

\author{
A. M. El-Sherif' ${ }^{1}$ A. Sayed ${ }^{2}$ \\ ${ }^{1}$ Department of Veterinary Medicine, Faculty of Veterinary Medicine, \\ Beni-Suef University, Beni-Suef, Egypt \\ ${ }^{2}$ El-Naser Company for Chemical Industries, Cairo, Egypt
}

\begin{abstract}
A total of 980 camels were employed in this study for evaluation of some diagnostic procedures used for diagnosis of camel trypanosomiasis. Clinical examination revealed that $180(18.37 \%)$ camels showed sings of illness including, loss of body weight, anemia, abortion, decrease of animal production and edema in some parts of the body. Parasitological examination of camel's blood smears revealed the presence of Trypanosoma evansi in $57(5.82 \%)$ camels. ELISA detected $99(63.06 \%)$ positive cases while suratex test identified $80(50.96 \%)$ positive cases. Results of mice inoculation test for detection of Trypanosoma evansi among camels showed that 69 $(43.95 \%)$ camels were positive. The present study clarified that suratex test was $100 \%$ sensitive for diagnosis of trypanosomiasis followed by ELISA (98.55\%).
\end{abstract}

Trypanosoma evansi infection is one of the most important diseases affecting camels in many countries of the world as a result of body wasting, anemia, abortion, decrease of production as well as increased susceptibility to other infectious diseases due to immune suppression (Igbokwe, 1989).

Surra disease; an Indian term means rotten and emaciated, is the most commonly used name for infection of camels with Trypanosoma evansi. Surra disease is transmitted mechanically by biting of fly vectors from camel to camel; therefore seasonal occurrence of trypanosomiasis is one of the important features of the disease.

Trypanosomiasis runs a variable course in diseased camels. Acute stage is characterized by high parasitaemia with demonstration of large numbers of the parasite in the blood while chronic stage is characterized by scanty or complete absence of the parasite (Losos, 1980).

Antibodies for Trypanosoma evansi were detected allover the course of the disease even during disappearance of the parasite due to effective therapy, therefore some researchers considered that antibody detecting assays as misleading diagnostic tools (Olaho-Mukani et al., 1996).

Circulating antigens of Trypanosoma evansi in camel's blood could be detected by using of latex agglutination test "Suratex" which is considered a direct indication of active infection (Wernery et al., 2001).
This study was carried out to evaluate some diagnostic procedures used in diagnosis of Trypanosoma evansi infection in camels including, parasitological examination, mice inoculation test, antibody detection by using of ELISA and detection of Trypanosoma evansi circulating antigens by Suratex test.

\section{Animals.}

\section{Material and Methods}

Camels. A total number of 980 camels including 360 camels imported from Sudan at Daraw quarantine, Aswan, Egypt and 620 camels from different localities in Egypt were used in this study.

Mice. White mice of 150-200 grams body weight were used in mice inoculation test after being proved free from Trypanosoma infection by examination of blood smears form tail vein.

\section{Samples.}

Camel's whole blood samples from the ear vein were collected to be used for parasitological examination and mice inoculation test. Blood serum samples were collected for serological examinations by using ELISA and Suratex test.

Trypanosoma evansi antigen. It was prepared according to (Lanham and Godfery 1970).

Suratex reagent. It was obtained from Trypanosomiasis Research Institute, Kenya.

Giemsa Stains. 0.68 solution in methanol/ glycerol was obtained from BHD chemicals, Ltd, Pool England. This solution was diluted and used for staining of blood smears.

Microscopical examination of blood smears. It 
was carried out according to (Coles, 1986).

Detection of antibodies of trypanosoma evansi using ELISA. It was carried out according to the method described by (Zweygarth et al., 1986).

Detection of circulating antigens by Suratex test. The test was done according to the method described by (Olaho-Mukani et al., 1996).

Mice inoculation test. It was carried according to the method described by (Godfrey and Killick-Kendrick, 1962).

\section{Results}

Clinical examination. Diseased camels revealed the following abnormalities: rise of body temperature in $12(0.012 \%)$ camels, loss of body condition, weakness and rough coat in 22 $(0.022 \%)$, severe emaciation that included atrophy of thighs, hump and prominent ribs of $34(0.034 \%)$ camels and edematous swelling of limbs in 7 cases.

Correlation between different diagnostic procedures employed in this study is shown in (Table 1).

Table 1: Correlation between the different diagnostic procedures.

\begin{tabular}{ccccc}
\hline Infectious status & $\begin{array}{c}\text { No. of examined } \\
\text { animals }\end{array}$ & $\begin{array}{c}\text { Parasitological } \\
\text { examination }\end{array}$ & Antibody ELISA & $\begin{array}{c}\text { Circulating } \\
\text { antigen (Suratex) }\end{array}$ \\
\hline MI +ve & $69(43.95 \%)$ & $57(36.31 \%)$ & $68(98.24 \%)$ & $69(37.21 \%)$ \\
MI -ve & $88(56.06 \%)$ & Zero $\%$ & $31(31.31 \%)$ & $11(13.75 \%)$ \\
Total No. & 157 & $57(36.31 \%)$ & $99(65.06 \%)$ & $80(50.96 \%)$ \\
\hline
\end{tabular}

+ve: positive

-ve: negative

MI: mice inoculation

Sensitivity of different tests was $82.61 \%$ for parasitological examination, $98.55 \%$ for ELISA and $100 \%$ for circulating antigen (Suratex) (Table 1).

\section{Discussion}

Trypanosoma evansi infection causes serious economical losses in camels due to the wasting nature of the disease (Njiru et al., 2000).

The clinical sings of diseased camels were rise in body temperature varied from $38.8-39^{\circ} \mathrm{C}$ in 12 camels, loss of conditions, weakness and variable degrees of coat roughness were observed in 22 camels, sever emaciation, atrophy of thighs and hump of 34 camels and edematous swellings in limbs of seven affected camels.

Results of parasitological examination of blood camel's smears showed that 57 camels were infected. These results indicated high prevalence of Trypanosoma evansi in camels. Similar findings were observed by (Diall et al., 1993).

In this study, Trypanosoma evansi was reported as the only causative agent of Trypanosomiasis, that was also reported by several authors (Mason, 1911; Abdel-Latif, 1957; Gad El-Moula and Fayed 1975; Nessiem, 1994; Abdel-Rady, 1997 and Madkour, 2002).

Mice inoculation test was applied for detection of Trypanosoma evansi infection amoung camels. This test was applied on a total of the 157 blood samples including the 57 blood samples, which gave positive results during blood smear examination. All the 57 blood samples that showed positive results in blood smear examination, gave positive results in this test in addition to 12 cases from which Trypanosoma evansi that could not be detected by blood smear examination. These results denoted the efficiency of mice inoculation test especially in camels that may show low number of parasites. Therefore, the test was recommended by several authors (Chaudhri et al., 1996 and Jain et al., 2000) as a reliable test.

Blood sera of 157 camels including the 57 camels that showed Trypanosoma evansi in their blood smears were subjected to ELISA test. 68 (98.24\%) animal out of the camels that showed trypanosomes in their blood were positive for ELISA. Among 88 camels that showed negative results for Trypanosoma evansi demonstration by blood smear, $31(35.22 \%)$ were found positive by ELISA test. The total results by ELISA reach to 99 positive camel $(63.06 \%)$. These results denoted high sensitivity of ELISA in detecting Trypanosoma evansi antibodies in camels. This test could identify 68 out of 69 Trypanosoma evansi confirmed cases. Moreover, ELISA could detect antibodies in 31 (31\%) cases out of 100 that failed to be detected 
by parasitological examination. Olaho-Mukani et al. (1996) stated that tests based on antibody detection such as ELISA are of little application in diagnosis of patent and sub-patent Trypanosoma evansi infection due to persistence of antibodies in the circulating blood for long periods even after cure. Luckin et al. (1978) reported that antibodies persist for 100 days or more after successful treatment. Boid et al. (1981) proved that ELISA does not distinguish between current infection and previous exposure. The obtained results indicated that presence of antibodies does not necessarily mean that trypanosomes are present.

The blood sera of the same 157 camels were subjected to a latex agglutination test, Suratex, for detection of Trypanosoma evansi circulating antigens. The results showed that circulating antigens were demonstrated in blood sera of all 69 camels that showed positive results in parasitological examination with $100 \%$ sensitivity. Suratex test also detected 11 (11\%) cases out of 100 camel sera that showed negative results by blood smear examination. Suratex test has been considered as much more sensitive than parasitological examinations where demonstration of antigens in the peripheral circulation is a direct indication of active infection. This test can also differentiate between current infection and cured one. This result was supported by (Olaho-Mukani et al. 1996). Suratex had been confirmed as a reliable test for diagnosis of camel Trypanosomiasis by many other authors: (El-Said, 1999; Njiru et al., 2000 and Wernery et al., 2001). This test also described as a simple rapid sensitive and specific test by (Natulyla and Diall 1998). Detection of Trypanosoma evansi antigen in the blood of infected camels even during absence of the parasite from blood stream makes this test more suitable and effective in diagnosis and consequently control of Trypanosomiasis. Moreover, Olaho-Mukani et al., (1992) reported that trypanosoma antigens disappear from blood circulation after an effective treatment.

This study proved that microscopical examination of infected camels is suitable only in acute cases while in chronic cases the parasites are scanty or absent completely, antibodies detection by ELISA is an effective method for diagnosis of Trypanosomiasis because antibodies are detectable even after recovery. Suratex is considered as an accurate, coast effective and sensitive test that can be applied under field conditions. In addition,
Suratex can be used for early detection of infection giving high chance for early treatment and control of the disease.

\section{References}

Abdel-Latif, K. (1957): The incidence of disease caused by intercorpuscular blood parasite in camels and their treatment with special reference to trypanosomiasis. M.V.Sc. Thesis, Fac. of Vet. Med., Cairo Univ., Egypt.

Abdel-Rady, A. (1997): Some epidemiological aspects of camel trypanosomiasis in Upper Egypt. M. V. Sci., Fac. Vet. Med., Assiut Univ., Egypt.

Boid, R.; El-Amin, E. A.; Mahmoud, M. M. and Luckins, A. G. (1981): Trypanosoma evansi infections and antibodies in goats, sheep and camels in the Sudan. Trop. Anim. Health Prod., 13: 141-146.

Chaudhri, S. S; Gupta, R. P. and Singh, V. (1996): Experimental trypanosomiasis in cross breed calves: its diagnosis and chemoprophylaxix. Ind. J. Anim. Sci., 66 (7): 662-665.

Coles, E. H (1986): Veterinary Clinical Pathology. $4^{\text {th }}$ ed. W.B. Saunders Company, Philadelphia, London, Toronto.

Diall, O.; Bocoum. Z.; Diarra, B.; Sanogo, Y.; Coulibaly, Z. and Waigalo, Y. (1993): Epidemiology de la trypanosomes a Trypanosoma evansi chez le dromedaire au Mali; Resultats denquetes Parasitologiques et clinquse. Revue Elev. Med. Vet. Pays Trop., 46, (3): 416-455.

El-Said, H. M. (1999): Diagnosis of chronic Trypanosoma evansi infection among serologically positive camels using a latex agglutination test for the detection of circulating trypanosomal antigens. Vet. Med. J. Giza, 47 (1): 67-74.

Gad El-Moula, B. I. and Fayed, A. A. (1975): The efficacy of suramin in the treatment of trypanosomiasis in the Egyptian camels under desert conditions. J. Egypt. Vet. Med. Assoc., (35): 65-70.

Godfrey, D. G. and Killick-Kendrick, R. (1962): Trypanosoma evansi in camels in Nigeria; a high incidence demonstrated by the inoculation of blood into rats. Annal Trop. Med. Parasitol., 56: 14-16.

Igbokwe, I. O. (1989): Dyserythropiosis in animal trypanosomiasis. Revue Elev. Med. Vet. Pays Trop., 42 (3): 423-429.

Jain, S.; Pareek, R.; Pathak, K. M. L. and Kapoor, M. (2000): Comparison of six different tests for the detection of Trypanosoma evansi in dromedaries. J. Camel Prac. Res., 7 (2): 215-217.

Lanham, S. M. and Godfrey, D. G. (1970): Isolation of salivarian trypanosomes from man and other mammals using DEAE-cellulose. Exp. Parasitol., 28: 521-534.

Luckins, A. G.; Gray, A. R. and Rae, P. (1978): Comparison of the diagnostic value of serum immunoglobulin levels, an enzyme linked immunosorbent assay and a fluorescent antibody test in experimental infection with Trypanosoma evansi in rabbits. Ann. Trop. Med. Parasitol., (72): 429-441.

Losos, G. J. (1980): Diseases caused by Trypanosoma evansi. A Review. Vet. Res., Comm., (4): 165-181.

Madkour, B. S. (2002): Role of imported camels in the epizootiology of some parasitic diseases. M. V. Sc., Fac. Vet. Med., Beni-Suef, Cairo Univ., Egypt.

Mason, F. E. (1911): A note on camel Trypanosomiasis of Egypt and result of first series experimental drug treatment. J. Comp. Pathol. Therap., (24): 47-49.

Natulyla, V. M. and Diall, O. (1998): Trypanosoma evansi infections: towards penside diagnosis. J. Protozool. Res., 8 (3): 185-189.

Nessiem, M. G. (1994) : Evaluation of the silicone 
centrifugation technique in the detection of Trypanosoma evansi infection in camels and experimental animals. Trop. Anim. Health Prod., 26 (4): 227-229.

Njiru, Z. K.; Ole-Mapeny, I. M.; Ouma, J. O.; Ndung, U. J. M. and Olaho-Mukani, W. (2000): Prevalence of Trypanosomiasis in camel calves: a pilot study in Laikipia District of Kenya. Revue' Elevage et de Medecine Veterinaire des Pays Tropicaux, 53 (2): 182-183.

Olaho-Mukani, W.; Munyua, W. K.; Njogu, A. R.; Mutugi, M. W.; Omuse, J. K.; and Sayer, P. D. (1992): Application of an antigen enzyme linked immunoassay for the diagnosis of Trypanosomiasis in camel in Kenya. Proc. $1^{\text {st }}$ Int. Camel Conf., pp. 33-36.
Olaho-Mukani, W.; Nyang'ao, J. M. and Ouma, J.O. (1996): Use of suratex for field diagnosis of patent and non-patent Trypanosoma evansi infection in camels. $\mathrm{Br}$. Vet. J., 152 (1): 109-111.

Wernery, U.; Zachariah, R., Mumford, J. A. and Luckins, T. (2001): Preliminary evaluation of diagnostic tests using horses experimentally infected with Trypanosoma evansi. Vet. J., 161 (3) 287-300.

Zweygarth, E.; Sabwa, C.; and Rottcher, D. (1986): An enzyme-linked immunosorbent assay for the detection of antibodies to Trypanosoma evansi in camels (Camelus dromedaries) using peroxidase conjugated protein A. Ann. Trop. Med. Parasitol., (37): 105-106. 